\title{
Increasing ecological multifunctionality during early plant succession
}

\author{
Susanne Winter · Markus Klemens Zaplata • Michael Rzanny • \\ Wolfgang Schaaf • Anton Fischer $\cdot$ Werner Ulrich $\mathbb{B}$
}

Received: 25 September 2018/ Accepted: 22 March 2019/Published online: 3 April 2019

(C) The Author(s) 2019

\begin{abstract}
Ecological multifunctionality quantifies the functional performance of various important plant traits and increases with growing structural habitat heterogeneity, number of plant functional traits, and species richness. However, the successional changes in multifunctionality have not been traced so far. We use quantitative plant samples of $1 \mathrm{~m}^{2}$ plots from the first 6 years of initial vegetation dynamics in a German created catchment to infer the temporal changes in plant functional trait space and multifunctionality.
\end{abstract}

Communicated by Lori Biederman.

S. Winter

Faculty of Forest and Environment, Section of Applied

Ecology and Zoology, Eberswalde University of

Sustainable Development, Alfred-Möller-Str. 5,

16225 Eberswalde, Germany

e-mail: Susanne.Winter@hnee.de

\section{K. Zaplata}

Hydrology and Water Resources Management, Brandenburg University of Technology CottbusSenftenberg, Siemens-Halske-Ring 10, 03046 Cottbus, Germany

e-mail: Markus.Zaplata@b-tu.de

\section{Rzanny}

Max-Planck-Institut für Biogeochemie, WG

Biogeochemical Processes, Hans-Knoell-Str. 10, 07743 Jena, Germany

e-mail: mrzanny@bgc-jena.mpg.de
Multifunctionality at the plot level was in all study years lower than expected from a random sample of the local pool of potential colonizers and was lowest at intermediate states of succession. In each year species containing a specific set of traits occurred with limited but focused functionality. The observed average low degree of multifunctionality contrasts with recent models predicting a tendency towards maximum multifunctionality during plant community development. However, variability in multifunctionality among plots increased during succession and the respective multifunctionality distribution among plots

\author{
W. Schaaf \\ Soil Protection and Recultivation, Brandenburg \\ University of Technology Cottbus-Senftenberg, Konrad- \\ Wachsmann-Allee 6, 03046 Cottbus, Germany \\ e-mail: wolfgang.schaaf@b-tu.de
}

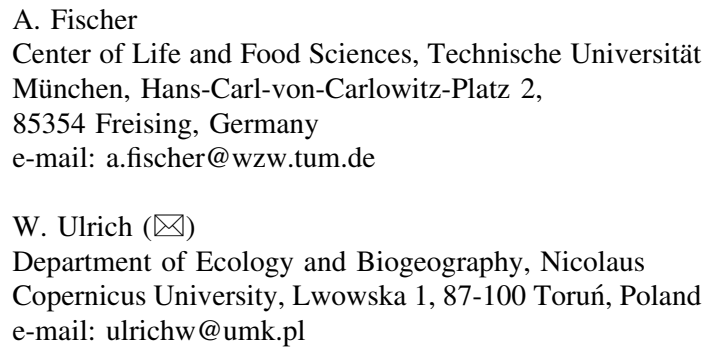


was increasingly right skewed indicating an excess of plots with relatively high multifunctionality. This relative excess of plots with high multifunctionality might act as an important trigger of community development paving the way for new species and functions to become established.

Keywords Primary succession - Multifunctionality · Environmental niche $\cdot$ Functional traits $\cdot$ Limiting similarity $\cdot$ Ecosystem services

\section{Introduction}

Primary plant succession is the result of initial colonization. Colonization and extinction events lead to a sequence of transient plant assemblages, where the first elements in this sequence result from stochastic processes (Miles 1987; Glenn-Lewin et al. 1992; Kahmen and Poschlod 2004; Marteinsdóttir et al. 2010) driven by the dispersal of propagules belonging to the regional species pool (Pickett et al. 1987). At later states species interactions, mainly priority effects (Helsen et al. 2012), mutual relations (Callaway and Walker 1997), and competition (Chesson 2000), as well as habitat filter effects (Wiens and Graham 2005) step in.

Stochastic colonization-extinction dynamics are well described by classical, species centered island biogeographic models (MacArthur and Wilson 1963) and their modern, individual centered extensions based on ecological drift (Hubbell 2001). However, these models are silent about the functional aspects of community assembly. In this respect, plant functional traits (PFTs) are defined as any trait which impacts fitness indirectly via its effects on growth, reproduction and survival (Violle et al. 2007). Particularly traits related to environmental demands (being subject to environmental filters) and traits directly linked to reproduction concur with this definition. Therefore, the plant species that occur at a specific state of succession should be characterized by a specific set of traits that allow colonization and survival. Consequently, our first starting hypothesis states that the sum of these realized traits, quantified by the total trait space, and the community functioning differ between subsequent successional states. These differences should reflect the dominant local habitat filters (Wiens and Graham 2005; Götzenberger et al. 2012).

In later successional states two contrasting mechanisms might act. First, succession might still be driven by stochastic species colonization. The distribution of traits might or might not reflect the respective distribution in the effective regional pool. Second, colonization success might depend on the trade-off between the sets of colonizer traits and those already established (Liu et al. 2013). Consequently, trait distributions should exhibit a non-random pattern that deviates from the respective distribution of the effective pool. New colonizers should have a greater probability of successful settlement if their traits differ from those of the already established species (Connell and Slatyer 1977; Prach and Walker 2011) making the total trait space larger than expected by chance. Under this scenario succession becomes trait driven (Schleicher et al. 2011). Importantly, colonizing and established plants interact with their environment altering abiotic conditions, and create a mosaic of increasingly heterogeneous microenvironments. This might facilitate the colonization of new species and allow for an increasingly broader spectrum of functional traits (Corenblit et al. 2015). Hence, our second hypothesis assumes that new colonizers should constantly add to the total trait space until the possible space is filled. Further, total trait space should not only be significantly larger than expected from a random sampling from the regional species pool but it should also be more evenly filled, that is the variance in the trait distribution should be smaller than expected by chance.

Evenly filled trait space is closely connected with the concept of ecological multifunctionality (Gamfeldt and Roger 2017). Multifunctionality, the manifold of ecological ecosystem services realized in a community (Hector and Bagchi 2007), quantifies the functional performance of various important traits within a single metric and has been shown to be positively correlated with structural habitat heterogeneity (Brown 1991; Alsterberg et al. 2017), species richness (Maestre et al. 2012; Lefcheck et al. 2015), and the equitability in species abundances (Gross et al. 2017). In turn, a minimum degree of diversity is necessary to uphold basic levels of multifunctionality for a given habitat type (Pasari et al. 2013). This minimum diversity increases with increasing functional complexity (Isbell et al. 2011). In the light of 
these findings it is straightforward to assume that multifunctionality increases with increasing richness during succession (third hypothesis).

However, Cousins and Lindborg (2004) and Schleicher et al. (2011) did not find any association between plant community assembly and selected functional traits during secondary grassland and sand dune colonization, respectively. These authors conclude that at least in their study systems succession is not trait driven. Other work also failed to identify simple links between environmental heterogeneity and functional trait diversity (Wiegleb and Felinks 2001; del Moral and Lacher 2005). By contrast, Prach et al. (1997) revealed a clear patterning in trait abundance during early secondary succession. Most traits increased and few traits decreased in their importance over time while some traits were unaffected. Finally, Ulrich et al. (2014) found total species trait space to steadily increase during early succession.

Total trait space and attribute diversity must not be confused with multifunctionality. Trait space refers to the total space spanned by the number of trait axes in Euclidean space and can be quantified for single sites, for instance, by a convex hull (Cornwell 2006). Multifunctionality refers to combined functional effects of traits in a single study site in comparison to other sites. Thus the calculation of multifunctionality needs data from many study sites and is a relative measure only (Maestre et al. 2012).

Traits are commonly divided into those that respond to environmental conditions (e.g., seed production) and those that have functional effects (e.g., biomass production and assimilation rates) although this division is by no means mutually exclusive (Lavorel and Garnier 2002). Both types of traits effect species composition, biodiversity, and species abundances (Violle et al. 2007). Importantly, Thompson and Gonzalez (2016) used meta-community modeling and showed the degree of realized multifunctionality in a community is highly dependent upon dispersal. In these models dispersal is able to promote multifunctionality by a trade-off between incoming and resident species and by mass effects allowing species to persist in suboptimal environments. This trade-off might cause multifunctionality to become highest at intermediate states of succession (4th hypothesis). However, these models have so far not been tested in field observations and it remains unknown whether and how multifunctionality changes during early succession.

Here we try to fill this gap in our knowledge. We use an extraordinary data set on the first six years of initial vegetation dynamics at the created catchment Chicken Creek, Eastern Germany, Fig. 1) containing geo-referenced information of species richness, traits, and soil conditions. Under the premise that the climatic and soil conditions at the study site only marginally changed during the first six years of succession, we assume that the occurrence or disappearance of plant functional traits at each state of succession is mainly the consequence of the interactions of arriving and resident species. Zaplata et al. (2013) have already demonstrated that the observed annual species turnover was mediated by the distribution of functional traits possessed by the resident species. However, Zaplata et al. (2013) also demonstrated the existence of clearly defined successional phases in richness and community composition with well-defined performance. Therefore, temporal changes in multifunctionality might be less pronounced than changes in species richness.

Based on this theoretical background we pose three basic questions:

(1) Does multifunctionality change during succession being highest at intermediates states?

(2) How is the change in multifunctionality linked to total trait space, species richness, and soil conditions?

(3) Do the observed levels of multifunctionality differ from the expectation of neutral community assembly?

\section{Material and methods}

Study area and sampling

From 2005 to 2011, we studied the early vegetation succession in a six ha constructed catchment 'Hühnerwasser' (Chicken Creek) within the partly decarburized lignite mine Welzow Süd in NE Germany (Fig. 1). Sand and loamy sand material originating from Pleistocene sediments were used for the construction of the 1-3.5 m top layer of the catchment to cover a 1-1.5 m clay layer (details in Gerwin et al. 2009). 
Fig. 1 geographical location of the German Chicken Creek catchment in August 2008 (aerial photograph provided by Vattenfall Europe Mining $\mathrm{AG})$ showing the positions of the $25-\mathrm{m}^{2}$ cells (A). In the cell corners four $1 \mathrm{~m}^{2}$ plots form a set (B)

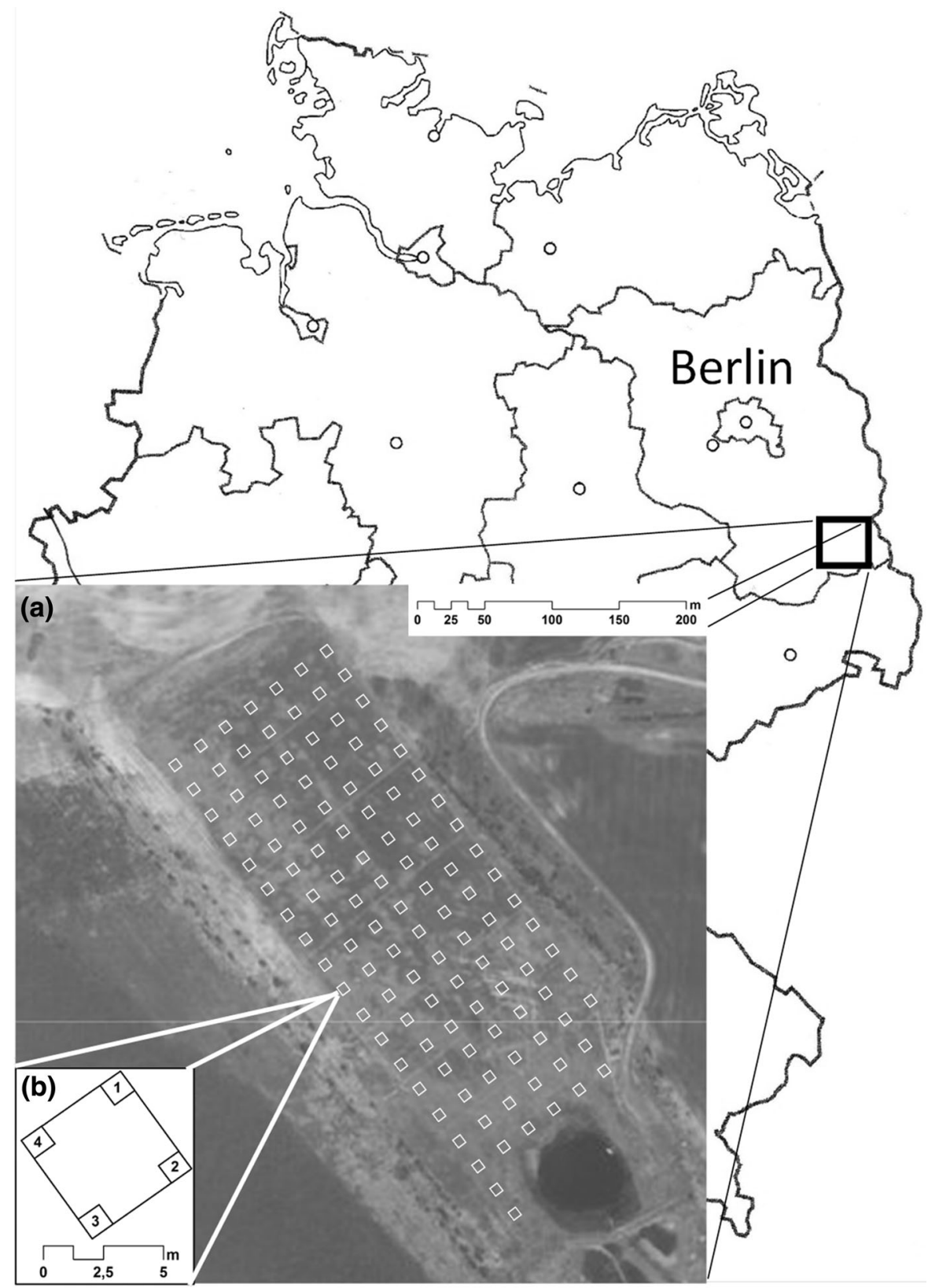

A $20 \mathrm{~m} \times 20 \mathrm{~m}$ grid net was established in October 2005, immediately after catchment construction ended on completion of the top layer. Within this grid, 119 25- $\mathrm{m}^{2}$ cells (Fig. 1), and, in their corners, 474 single plots of $1-\mathrm{m}^{2}$ (Zaplata et al. 2010) underwent a census in terms of both quality (species) and quantity (species cover). Vegetation was first recorded in 2005 on $3601-\mathrm{m}^{2}$ plots, and since 2006 annually on all plots and cells. As the vegetation was initially very sparse with generally only single plant occurrences per plot we used only the data from 2006 to 2011 . We also excluded 48 divergent plots of semiquatic nature near a pond (Fig. 1) leaving a total of 426 plots. The complete data of species abundances of all study years used in this study are already contained in Ulrich et al. (2016). From these surveys we constructed species abundance matrices (species in rows, samples in columns) for each study year. 
We considered six topsoil properties $(0-30 \mathrm{~cm})$ for our analyses: $\mathrm{pH}$, soil carbonate, organic carbon, nitrogen, sulfur, and sand content in 0-30 cm depth). Substrate samples were taken at all grid points in 2005. All raw data are contained in Gerwin et al. (2011).

We used the Leda (Kleyer et al. 2008) and BioFlor (Klotz et al. 2002) databases and compiled a total of two plant morphological traits (specific leaf area, canopy height), four environmental demand traits assessed by Ellenberg indicator values (Ellenberg et al. 1992) (light, humidity, $\mathrm{pH}$, nitrogen), and three dispersal traits (seed number, seed weight, seed longevity). Morphological and demand classes are directly linked to ecosystem functionality. High values in each of these traits indicate increased matter cycling and photosynthetic activity (Chapin III 2003). Based on seed weight and dispersal mode, we further classified the plants into three dispersal classeslow, intermediate, and highly dispersive - that might be important for colonization during early succession (Schleicher et al. 2011; Sanaphre-Villanueva et al. 2017). Missing values were in all cases replaced by the respective values of the nearest relatives (always congeners). All species trait data used in the present study are contained in Ulrich et al. (2017).

In the next step we calculated for each of these traits $i$ the abundance weighted trait value $\left(T_{i, j}\right)$ at each of the plots $j$ as the sum of all trait values $\left(T_{i, j}=\right.$ $\left.\sum_{k=1}^{S} p_{k} t_{i, k}\right)$, where $p_{k}$ denotes the relative abundance of species $k$ and $t_{i, k}$ is the associated value of trait $i$. As absolute trait values differ amongst traits, we followed Maestre et al. (2012) and Gross et al. (2017) and normalized total trait expressions for each plot using standardized effect sizes $\left(Z_{i, j}=\frac{T_{i, j}-\mu_{i}}{\sigma_{i}}\right)$, where $\mu_{i}$ and $\sigma_{i}$ refer to the average $T_{i, j}$ and the respective standard deviation among the $j$ plots. This transformation allows for an additive combination of the $Z_{i, j}$ values.

Trait and multifunctionality analysis

We followed Ulrich et al. (2014) and calculated for the three trait groups (morphology, environmental demands, dispersal) the functional attribute diversity (FAD, Walker et al. 1999) as a measure of total trait space covered by the species found in a given plot. It is calculated as the standardized effect size $\left(F A D=\frac{O_{E}-E_{E}}{\sigma_{E}}\right)$, where $O_{\mathrm{E}}$ and $E_{\mathrm{E}}$ refer to the sum of observed and expected, respectively, Euclidean distances between all species in trait space and $\sigma_{\mathrm{E}}$ is the standard deviation of the distribution of expected values. $E_{\mathrm{E}}$ and $\sigma_{\mathrm{E}}$ were based on 200 random reshufflings of the values of each trait among the total number of species present in each year. We used this number, and not the total number of species observed during all study years, as we assumed that the relatively large study area (6 ha) and the high number of plots captured every year meant a high percentage of the effective species pool was able to colonize the area at each state of succession. In turn, using all observed species would artificially inflate the annual null space as species observed in later states only might not be able to colonize earlier states.

Byrnes et al. (2014) recommended quantifying multifunctionality by the number of trait values that simultaneously exceed a given threshold. Following Maestre et al. (2012) and Gross et al. (2017) we established this threshold from the Z-transformed total trait expressions $Z_{i, j}$ and obtained for each of the three trait groups a measure of multifunctionality $M_{\mathrm{j}}$ for each community $j$ as the average $Z_{i, j}$ for the traits within each group (Byrnes et al. 2014). We did not calculate single degree of multifunctionality for all traits because such a value would combine traits that act at very different levels, influencing community functioning either direct (demands and dispersal) and indirect (morphology). Under the assumption that the $Z_{i, j}$ values are approximately normally distributed $M_{j}$ values $>2.0$ indicate a significant degree of multifunctionality. In turn $M_{\mathrm{j}}<-2.0$ indicates a functionally depauperated community. To compare observed multifunctionality among plots and study years we used again a null model approach and compared observed values with those obtained from 200 random reshufflings of the traits among species.

Our study design enabled us to link observed degrees of multifunctionality to plot richness, soil characteristics, and study years (using general linear modeling with identity link function and normal error structure). The multiple sampling of the same plots would have inflated the error degrees of freedom. Therefore, for calculating parametric significances we reduced the number of error degrees of freedom to the number of plots $(N=426)$. We quantified the variability in composition among plots using the plot $x$ plot Euclidean dissimilarity matrix of multifunctionality and the respective Bray-Curtis dissimilarity 
matrices for species abundances, plot spatial distances, and soil characteristics. We related these matrices by the Mantel correlation.

\section{Results}

Functional attribute diversity (FAD) was in all study years lower than expected from an equiprobable reshuffling of traits among species (Fig. 2a). Respective standardized effect sizes (SES) decreased during succession, particularly with respect to dispersal and morphological traits (Fig. 2a). FAD and multifunctionality $(M)$, and also SES FAD and SES $M$ were not significantly correlated for any of the three trait classes (all Pearson $r<0.01, P<0.05$ and Table 1).

Multifunctionality (Fig. 2b) was negative during the first six study years and started to be positive in the last year. Variability in multifunctionality among plots increased in the last three study years (Fig. 2b). Respective standardized effect sizes were significantly negative irrespective of trait group and study year (Fig. 2c). This holds particularly for the environmental demands having average SES values well below 2.0 (Fig. 2c). Importantly, for all three classes the lowest SES $M$ values were observed at intermediate states of succession.

Multifunctionality did not markedly depend on soil characteristics (Table 1). Only soil nitrogen content consistently returned a weak signal pointing to a positive effect of $\mathrm{N}$ content on the degree of multifunctionality. In turn, plot species richness was positively correlated with multifunctionality for the three trait classes and explained between 8 and $17 \%$ of variance in SES $M$ (Table 1). Mantel correlations between multifunctionality $(M)$ and soil characteristics corroborated these results and were insignificant for all three trait classes $\left(r^{2}<0.01\right.$, permutation $P<$ $0.1)$.

The distribution of multifunctionality across plots was not symmetrical (Fig. 3). Having by definition an average of zero across plots, the multifunctionality distributions were significantly right skewed (except for the year 2011) having an excess of plots with high multifunctionality. This effect was largest at intermediate states of succession (Fig. 3a). Only in the last study year the multifunctionality distribution was approximately symmetrical (Fig. 3a). In turn, standardized effect sizes of multifunctionality decreased during succession. The excess of plots with comparably high degrees of multifunctionality at the beginning of the successional series turned into an excess of plots with too low multifunctionality (compared to the null expectation) in the last study years (Fig. 3b). However, within each study year SES $M$ significantly increased with plot richness (Table 1).

\section{Discussion}

Multifunctionality quantifies the variety of ecological functions performed by a given community. Because (a)

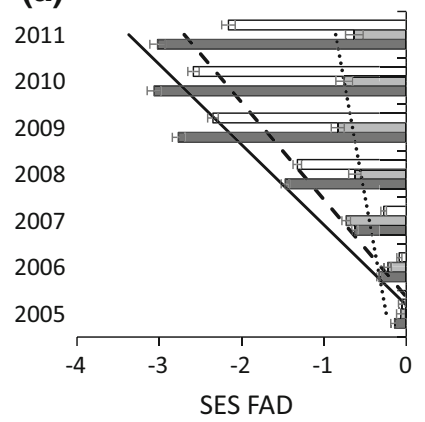

(b)

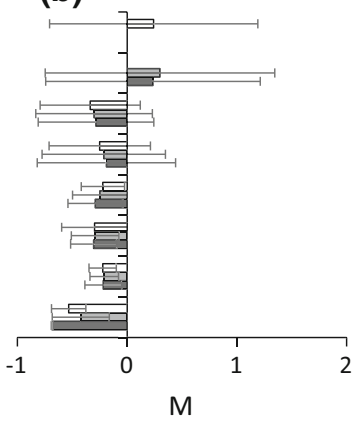

(c)

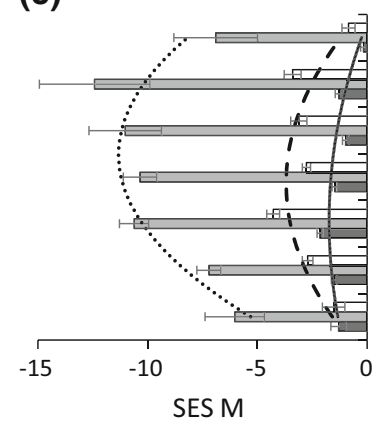

Fig. 2 Standardized effect sizes of functional attribute diversity (SES FAD) decreased during succession (a). Multifunctionality $M$ (given are median values) increased during succession (b) and the respective standardized effect sizes (SES M) were lowest at intermediate states of succession (b). White bars: dispersal traits, gray bars: environmental demand traits, dark gray bars: morphological traits. Error bars denote standard errors in $\mathbf{a}$ and $\mathbf{c}$ and lower and upper $75 \%$ quantiles in $\mathbf{b}$. Linear regressions in (a) are significant at permutation $P<0.05$, second order polynomial regressions in 9c) at permutation $P<0.10$ 
Table 1 General linear modeling with standardized effect sizes of multifunctionality (SES M) of dispersal, environmental, and morphological traits as dependent, study years as categorical, and plot richness ( $\alpha$-diversity), soil characteristics

\begin{tabular}{|c|c|c|c|c|c|c|c|}
\hline \multirow[t]{2}{*}{ Variable } & \multirow[t]{2}{*}{ df } & \multicolumn{2}{|c|}{ Dispersal } & \multicolumn{2}{|c|}{ Environment } & \multicolumn{2}{|c|}{ Morphology } \\
\hline & & $\beta$ & Partial $\eta^{2}$ & $\beta$ & Partial $\eta^{2}$ & $\beta$ & Partial $\eta^{2}$ \\
\hline Study year & 6 & - & $0.08 * * *$ & - & $0.16 * * *$ & - & $0.08 * * *$ \\
\hline$\alpha$-Diversity & 1 & 0.72 & $0.08 * * *$ & 0.75 & $0.17 * * *$ & 0.51 & $0.11 * * *$ \\
\hline $\mathrm{pH}$ & 1 & 0.07 & $<0.01$ & 0.07 & $<0.01$ & 0.05 & $<0.01$ \\
\hline $\mathrm{CaCO}_{3}$ & 1 & -0.08 & $<0.01$ & -0.11 & $<0.01$ & -0.07 & $<0.01$ \\
\hline $\mathrm{C}$ & 1 & 0.01 & $<0.01$ & 0.02 & $<0.01$ & 0.01 & $<0.01$ \\
\hline $\mathrm{N}$ & 1 & 0.15 & $0.01 *$ & 0.16 & $0.01 *$ & 0.11 & $0.01 *$ \\
\hline$S$ & 1 & -0.02 & $<0.01$ & -0.01 & $<0.01$ & -0.01 & $<0.01$ \\
\hline Sand & 1 & -0.01 & $<0.01$ & -0.02 & $<0.01$ & -0.01 & $<0.01$ \\
\hline SES FAD & 1 & -0.01 & $<0.01$ & -0.01 & $<0.01$ & 0.06 & $<0.01$ \\
\hline$r^{2}$ (model) & & & 0.21 & & 0.23 & & 0.21 \\
\hline
\end{tabular}

Given are degrees of freedom effect, $\beta$-values of the metric variables, partial $\eta^{2}$ values, and parametric significances $(* P<0.05$, $* * * P<0.001$ ) based on 426 error degrees of freedom (the number of plots)

early plant succession proceeds by a sequence of successional states (Zaplata et al. 2013) characterized by well-defined communities and sets of traits, our first starting question asked whether such a step-wise successional series translates into respective states of multifunctionality. This was indeed the case. The study years differed significantly in the degree of multifunctionality and also in functional space (Table 1; Fig. 1). In this respect our study is apparently the first to show such a step-wise development of functionality during succession.

Recently, Gross et al. (2017) have argued that climax dryland plant community assembly creates communities close to maximum multifunctionality. As this study used the same methodological framework as the present one, we can compare their results to ours. However, we note that our study system has not reached the climax yet. In middle Europe climax states are typically mixed deciduous forests (Bazzaz 1996). Clearly, early and middle successional plant communities are far from maximizing multifunctionality (Fig. 2b). Our results indicate a respective gradual development towards later successional states, where intermediate states have a low degree of functionality. However, multifunctionality increased significantly in the final two study years (Fig. 2b, c). Further, the proportion of plots with a positive level of multifunctionality increased in the last study year to
$(\mathrm{pH}$, inorganic and organic carbon, nitrogen, sulfur, and proportion of sand), and functional attribute diversity (SES FAD) as metric predictors 

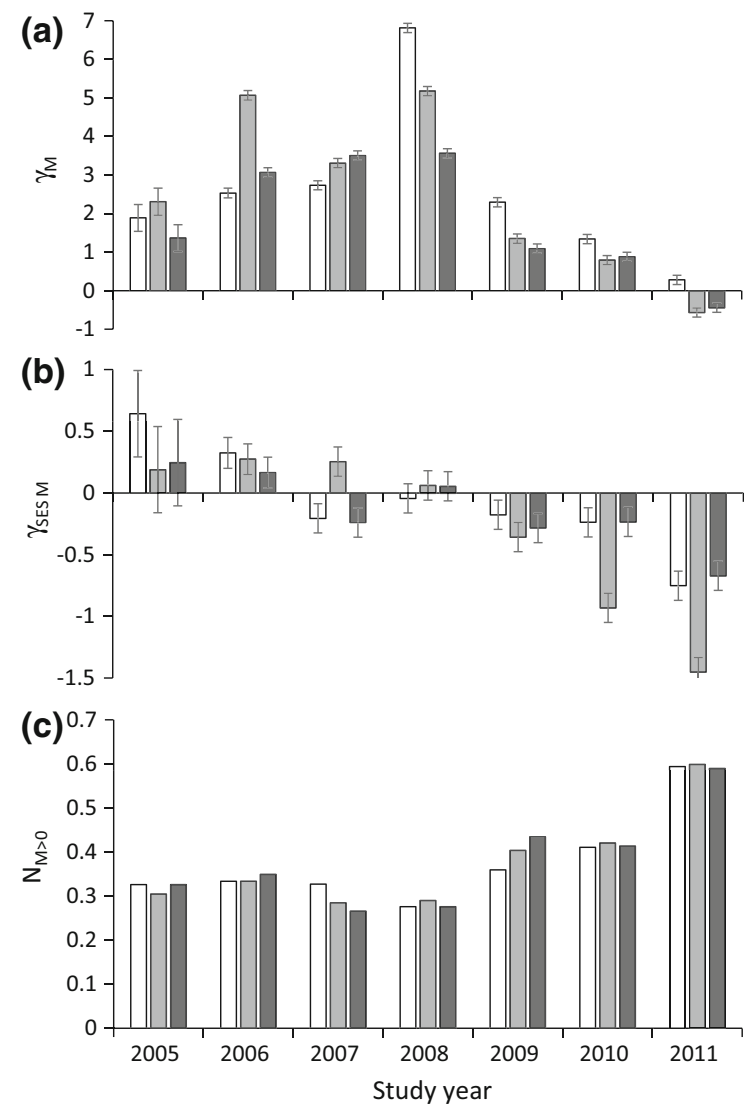

Fig. 3 Annual changes in skewness of the raw $M$ distributions $\left(\gamma_{M}: \mathbf{a}\right)$ and the distributions of the standardized effect sizes of $M\left(\gamma_{\mathrm{SES}}\right.$ : b). c proportions of plots with $M>0$. White bars: dispersal traits, light gray bars: environmental demand traits, dark bars: morphological traits. Errors refer to parametric standard errors

which account for differences in species richness among plots, should not deviate from those expected from random samplings as formulated in our third starting question. This was not the case (Fig. 2c). Apparently, in each year the trait distribution was too narrow to cover the possible functional space. In this respect, Loughnan and Gilbert (2017) have demonstrated how competitive interactions drive newly colonizing plants towards trait convergence. Such a convergence would automatically translate into reduced trait space and multifunctionality with respect to the species pool. However, in a previous work (Ulrich et al. 2017) we have shown that competitive interactions were only visible at small spatial scales and had only marginal impact on the annual species composition of the whole study area. Therefore we conclude that negative species interactions have at most a minor impact on trait composition and functionality.

Our null model that compared the communities at the plot scale with those expected from a random draw from all species that were able to colonize the study area pointed to relatively low degrees of multifunctionality. Apparently, in each year a specific set of traits occurred with limited but focused functionality. This is a clear indication of filter effects constraining the functional trait space and consequently the level of multifunctionality. At small spatial scales negative species interactions that lead to competitive exclusion might further reduce multifunctionality. Such an explanation is also backed by the significant annual differences in multifunctionality (Table 1).

At the beginning of succession few pioneer species have a trait composition that enables them to colonize bare soils (Schiffers et al. 2010). Subsequent mutualistic effects might help newly incoming species to fill the available trait space. On the one hand mutualism can be seen as an additional habitat filter where colonization is only possible if the partners are already present. On the other hand mutualism might relax abiotic filters and thus contribute to functionality. Importantly, new colonizers are rare at the beginning making the dynamics of multifunctionality particularly linked to species with low occupancy (Soliveres et al. 2016). Indeed the annual proportion of rare species (those with only a single occurrence) was positively linked to the $\mathrm{SES}_{\mathrm{M}}$ for dispersal (Pearson $r=0.52)$ and morphological traits $(r=0.68)$ although this was statistically not significant at the $1 \%$ error level due to the low number of study years. However, the fact that intermediate successional states had the lowest degree of multifunctionality and that multifunctionality was in all study years below the level expected from a random assembly of species clearly shows that the variety of species with different traits determines multifunctionality more than community composition. This again is an indication that at each successional state, biotic and abiotic filter effects constrain the community to members with similar trait configuration.

Soil characteristics are assumed to be strong filters for plant growth. However, in our study system they did not significantly influence the degree of multifunctionality (Table 1). Robroek et al. (2017) have recently demonstrated that the contribution of ferns to 
plant multifunctionality is negatively correlated to soil humidity. Unfortunately, small-scale variability in soil humidity was not assessed directly in the entire study area. In previous studies on the Chicken Creek system we have shown that the variability in soil carbon and sand content, as well as $\mathrm{pH}$ shaped small-scale phylogenetic structures (Ulrich et al. 2014) but not the pattern of species co-occurrences (Ulrich et al. 2016) and the spatial distribution of traits (Ulrich et al. 2017). This low influence of abiotic habitat conditions implies that functionality during plant succession was driven by other filter processes, possibly soil humidity. After the emergence of the first woody plants in 2007 increasing habitat differentiation accentuated the roles of microclimate and shade as additional strong filter agents (Schaaf et al. 2017).

A major result of the present study regards the detection of highly right skewed multifunctionality distributions particularly in the first years of succession (Fig. 3a). Despite the comparably low average degree of multifunctionality in these years there was an excess of plots with a higher level, i.e., with higher multifunctionality than expected from a random draw from the regional species pool (Fig. 3c). This proportion increased in the last study years to more than $60 \%$. We speculate that plots with high multifunctionality are important triggers of community development as they might be major agents in changing soil and microclimatic conditions by paving the way for new species to establish. Such an argument would be in line with recent notions that variability is a major stabilizing factor of ecological systems (Maestre et al. 2012; Tredennick et al. 2017). Future studies have to show whether the observed high variability in multifunctionality is indeed an engine of ecosystem development.

Acknowledgements This study was part of the TransRegio Collaborative Research Centre 38 (SFB/TR 38: ecosystem assembly and succession), which was financially supported by the Deutsche Forschungsgemeinschaft (DFG, Bonn) and the Brandenburg Ministry of Science, Research and Culture (MWFK, Potsdam). The authors thank the working group Z1 (monitoring) members of the SFB/TR 38, who helped us to perform this study and the Vattenfall Europe Mining AG for providing the research site. WU acknowledges funding from the Polish National Science Centre (2014/13/B/NZ8/04681). Hazel Pearson kindly improved our English.

Open Access This article is distributed under the terms of the Creative Commons Attribution 4.0 International License (http:// creativecommons.org/licenses/by/4.0/), which permits unrestricted use, distribution, and reproduction in any medium, provided you give appropriate credit to the original author(s) and the source, provide a link to the Creative Commons license, and indicate if changes were made.

Author contributions WU provided the theoretical background and performed analyzes, SW and AF developed the field design, MKZ, SW and AF collected the floristic data and created the database. WS analyzed the soil data. MR compiled the trait data. WU and SW wrote the first draft of the manuscript, and all authors contributed to revisions.

\section{References}

Alsterberg C, Roger F, Sundbäck K, Juhanson J, Huth S, Hallin S, Gamfeldt M (2017) Habitat diversity and ecosystem multifunctionality - the importance of direct and indirect effects. Sci Adv 3:e1601475

Bazzaz FA (1996) Plants in changing environments. Cambridge University Press.

Brown VK (1991) The effects of changes in habitat structure during succession in terrestrial communities. In: Bell SS, McCoy ED, Mushinsky HR (eds) Population and community biology series 8: habitat structure. Springer, Dordrecht, pp 141-168

Byrnes JEK, Gamfeldt L, Isbell F, Lefcheck JS, Griffin JN, Hector A, Cardinale BJ, Hooper DU, Dee LE, Duffy JE (2014) Investigating the relationship between biodiversity and ecosystem multifunctionality: challenges and solutions. Method Ecol Evol 5:111-124

Callaway RM, Walker LR (1997) Competition and facilitation: a synthetic approach to interactions in plant communities. Ecology 78:1958-1965

Chapin FS III (2003) Effects of plant traits on ecosystem and regional processes: a conceptual framework for predicting the consequences of global change. Ann Bot 91:455-463

Chesson P (2000) Mechanisms of maintenance of species diversity. Ann Rev Ecol Syst 31:343-366

Connell JH, Slatyer RO (1977) Mechanisms of succession in natural communities and their role in community stability and organization. Am Nat 111:1119-1144

Corenblit D, Davies NS, Steiger J, Gibling MR, Bornette G (2015) Considering river structure and stability in the light of evolution: feedbacks between riparian vegetation and hydrogeomorphology. Earth Surf Proc Landf 40:189-207

Cornwell WK, Schwilk DW, Ackerly DD (2006) A trait-based test for habitat filtering: convex hull volume. Ecology 87:1465-1471

Cousins SAO, Lindborg R (2004) Assessing changes in plant distribution patterns-indicator species versus plant functional types. Ecol Indic 4:17-27

Del Moral R, Lacher IL (2005) Vegetation patterns 25 years after the eruption of Mount St. Helens Washington, USA. Am J Bot 92:1948-1956 
Ellenberg H, Weber HE, Düll R, Wirth V, Werner W, Paulissen D (1992) Zeigerwerte von Pflanzen in Mitteleuropa. Scr Geobot 18:1-248

Gamfeldt L, Roger F (2017) Revisiting the biodiversityecosystem multifunctionality relationship. Nat Ecol Evol 1:0168

Gerwin W, Schaaf W, Biemelt D, Fischer A, Winter S, Hüttl RF (2009) The artificial catchment 'Chicken Creek' (Lusatia, Germany): a landscape laboratory for interdisciplinary studies of initial ecosystem development. Ecol Eng 35:1786-1796

Gerwin W, Schaaf W, Biemelt D, Winter S, Fischer A, Veste M, Hüttl RF (2011) Overview and first results of ecological monitoring at the artificial watershed Chicken Creek (Germany). Phys Chem Earth 36:61-73

Glenn-Lewin DC, van der Maarel E (1992) Patterns and processes of vegetation dynamics. In: Glenn-Lewin DC, Peet RK, Veblen TT (eds) Plant succession: theory and prediction. Chapman \& Hall, London, pp 11-59

Götzenberger L, de Bello F, Brathen KA, Davison J, Dubuis A, Guisan A, Leps J, Lindborg R, Moora M, Pärtel M, Pellissier L, Pottier J, Vittoz P, Zobel K, Zobel M (2012) Ecological assembly rules in plant communities: approaches, patterns and prospects. Biol Rev 87:111-127

Gross N, Le Bagousse-Pinguet Y, Liancourt P, Berdugo M, Gotelli NJ, Maestre FT (2017) Functional trait diversity maximizes ecosystem multifunctionality. Nat Ecol Evol 1:0132

Hector A, Bagchi R (2007) Biodiversity and ecosystem multifunctionality. Nature 448:188-190

Helsen K, Hermy M, Olivier H (2012) Trait but not species convergence during plant community assembly in restored semi-natural grasslands. Oikos 121:2121-2130

Hubbell SP (2001) The unified neutral theory of biogeography and biodiversity. Princeton University Press, Princeton

Isbell F, Calcagno V, Hector A, Connolly J, Harpole WS, Reich PB, Scherer-Lorenzen M, Schmid B, Tilman D, van Ruijven J, Weigelt A, Wilsey BJ, Zavaleta ES, Loreau M (2011) High plant diversity is needed to maintain ecosystem services. Nature 477:199-202

Jucker T, Coomes DA (2012) Comment on "Plant Species Richness and Ecosystem Multifunctionality in Global Drylands". Science 337:155

Kahmen S, Poschlod P (2004) Plant functional trait responses to grassland succession over 25 years. J Veg Sci 15:21-32

Kleyer M, Bekker RM, Knevel IC, Bakker JP, Thompson K, Sonnenschein M, Poschlod P, van Groenendael JM, Klimes L, Klimesová J, Klotz S, Rusch GM, Hermy M, Adriaens D, Boedeltje G, Bossuyt B, Dannemann A, Endels P, Götzenberger L, Hodgson JG, Jackel A-K, Kühn I, Kunzmann D, Ozinga WA, Römermann C, Stadler M, Schlegelmilch J, Steendam HJ, Tackenberg O, Wilmann B, Cornelissen JHC, Eriksson O, Garnier E, Peco B (2008) The LEDA traitbase: a database of life-history traits of Northwest European flora. J Ecol 96:1266-1274

Klotz S, Kühn I, Durka W (2002) BIOFLOR - eine Datenbank mit biologisch-ökologischen Merkmalen zur Flora von Deutschland. Schriften Vegetationsk 38, 334 S.

Lavorel S, Garnier E (2002) Predicting changes in community composition and ecosystem functioning from plant traits: revisiting the Holy Grail. Funct Ecol 16:545-556
Lefcheck JS, Byrnes JEK, Isbell F, Gamfeldt L, Griffin JN, Eisenhauer N, Hensel MJS, Hector A, Cardinale BJ, Duffy JE (2015) Biodiversity enhances ecosystem multifunctionality across trophic levels and habitats. Nat Commun 6:6936

Liu Q-X, Doelman A, Rottschäfer V, de Jager M, Herman PMJ, Rietkerk M, van de Koppel J (2013) Phase separation explains a new class of self-organized spatial patterns in ecological systems. Proc Natl Acad Sci USA 110:11905-11910

Loughnan D, Gilbert B (2017) Trait-mediated community assembly: distinguishing the signatures of biotic and abiotic filters. Oikos 126:1112-1122

MacArthur RH, Wilson EO (1963) An equilibrium theory of insular zoogeography. Evolution 17:373-387

Maestre FT, Quero JL, Gotelli NJ et al (2012) Plant species richness and ecosystem multifunctionality in global drylands. Science 335:214-218

Marteinsdóttir B, Svavarsdóttir K, Thórhallsdóttir TE (2010) Development of vegetation patterns in early primary succession. J Veg Sci 21:531-540

Miles J (1987) Vegetation succession: past and present perceptions. In: Gray AJ, Crawley MJ, Edwards PJ (eds) Colonization, succession and stability. Blackwell, Oxford, pp 1-29

Pasari JR, Levi T, Zavaleta ES, Tilman D (2013) Several scales of biodiversity affect ecosystem multifunctionality. Proc Natl Acad Sci USA 110:10219-10222

Pickett STA, Collins SL, Armesto JJ (1987) A hierarchical consideration of causes and mechanisms of succession. Vegetatio 69:109-114

Prach K, Pysek P, Smilauer P (1997) Changes in species traits during succession. A search for pattern. Oikos 79:201-205

Prach K, Walker LR (2011) Four opportunities for studies of ecological succession. Trends Ecol Evol 26:119-123

Robroek PJM, Jassey VEJ, Beltman B, Hefting MM (2017) Diverse fen plant communities enhance carbon-related multifunctionality, but do not mitigate negative effects of drought. R Soc Open Sci 4:117449

Sanaphre-Villanueva L, Dupuy JM, Andrade JL, Reyes-Garcia C, Jackson PC, Paz H (2017) Patterns of plant functional variation and specialization along secondary succession and topography in a tropical dry forest. Environ Res Lett 12:055004

Schaaf W, Pohle I, Maurer T, Gerwin W, Hinz C, Badorreck A (2017) Water balance dynamics during ten years of ecological development at Chicken Creek catchment. Vadoze Zone J https://doi.org/10.2136/vzj2017.04.0074

Schiffers K, Tielbörger K, Jeltsch F (2010) Changing importance of environment factors driving secondary succession on molehills. J Veg Sci 21:500-506

Schleicher A, Peppler-Lisbach C, Kleyer M (2011) Functional traits during succession: is plant community assembly traitdriven? Preslia 83:347-370

Soliveres S, Maestre FT, Ulrich W, Manning P, Boch S, Bowker M, Prati P, Fischer M, Delgado-Baquerizo M, Quero JL, Schöning I, Gallardo A, Weisser WW, Müller J, GarcíaGómez M, Ochoa V, Schulze E-D, Allan E (2015) Intransitive competition is widespread in plant communities and maintains species richness. Ecol Lett 18:790-798 
Soliveres S, Manning P, Prati D, Gossner MM, Alt F et al. (2016) Locally rare species influence grassland ecosystem multifunctionality. Philos Trans R Soc Lond B. https://doi. org/10.1098/rstb.2015.0269

Thompson PL, Gonzalez A (2016) Ecosystem multifunctionality in metacommunities. Ecology 97:2867-2879

Tredennick AT, Adler PA, Adler FR (2017) The relationship between species richness and ecosystem variability is shaped by the mechanism of coexistence. Ecol Lett 20:958-968

Ulrich W, Piwczyński M, Zaplata MK, Winter S, Schaaf W, Fischer A (2014) Soil conditions and phylogenetic relatedness influence total community trait space during early plant succession. J Plant Ecol 7:321-329

Ulrich W, Zaplata MK, Winter S, Schaaf W, Fischer A, Soliveres S, Gotelli NJ (2016) Species interactions and random dispersal rather than habitat filtering drive community assembly during early plant succession. Oikos 125:698-707

Ulrich W, Zaplata MK, Winter S, Fischer A (2017) Spatial distribution of functional traits indicates small scale habitat filtering during early plant succession. Persp Plant Ecol Evol Syst 28:58-66

Violle C, Navas ML, Vile D, Kazakou E, Fortunel C, Hummel I, Garnier E (2007) Let the concept of trait be functional! Oikos 116:882-892
Walker B, Kinzig A, Langridge J (1999) Plant attribute diversity, resilience, and ecosystem function: the nature and significance of dominant and minor species. Ecosystems 2:95-113

Wiegleb G, Felinks B (2001) Predictability of early stages of primary succession in post-mining landscapes of Lower Lusatia, Germany. Appl Veg Sci 4:5-18

Wiens JJ, Graham CH (2005) Niche conservatism: integrating evolution ecology and conservation biology. Ann Rev Ecol Syst 36:519-539

Zaplata MK, Fischer A, Winter S (2010) Vegetation dynamics. In: Schaaf W, Biemelt D, Hüttl RF (eds) Ecosystem development 2: initial development of the artificial catchment "Chicken Creek"-Monitoring Program and Survey, 2005-2008. Brandenburg University of Technology, Cottbus, Germany, pp 71-96

Zaplata MK, Winter S, Fischer A, Kollmann J, Ulrich W (2013) Species-driven phases and increasing structure in earlysuccessional plant communities. Am Nat 181:E17-27

Publisher's Note Springer Nature remains neutral with regard to jurisdictional claims in published maps and institutional affiliations. 